\title{
[Ru(arene)(diamine)] catalysts in ionic liquids: recyclable catalytic systems for transfer hydrogenation
}

\author{
Jean-Michel Joerger, ${ }^{a}$ Jean-Marc Paris, $^{\mathrm{b}}$ and Michel Vaultier ${ }^{\mathrm{a}, *}$

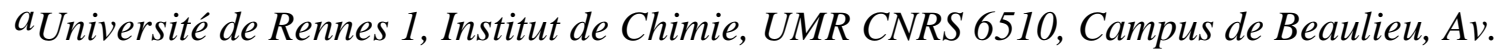 \\ Général Leclerc, 35042 Rennes, France

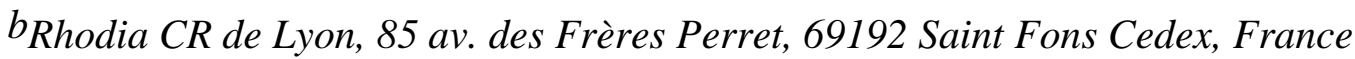 \\ E-mail: michel.vaultier@univ-rennes1.fr
}

To Professor Armand Lattes, for his $\mathbf{5 0}$ years of deep dedication to research and teaching

\begin{abstract}
[Ru(arene)(diamine)] catalysts have been immobilized in a variety of ionic liquids for asymmetric transfer hydrogenation of acetophenone. Catalyst recycling is possible with several ionic liquids, and enantiomeric excess is well maintained.
\end{abstract}

Keywords: Asymmetric transfer hydrogenation, ionic liquids, catalyst recycling

\section{Introduction}

Asymmetric transfer hydrogenation of prochiral ketones using either 2-propanol or formic acid as the hydrogen source has become an attractive method for the synthesis of chiral alcohols and amines. ${ }^{1}$ [Ru(arene)(diamine)] complexes, such as the precatalyst $\mathbf{1}$ developed by Noyori et al., have shown a good reliability for high enantiomeric excesses on a variety of substrates. ${ }^{2,3}$ Immobilization of these catalysts for the purpose of catalyst recovery or straightforward product separation has attracted much attention. ${ }^{4}$ Concerning 1, many research groups have immobilized this complex with sometimes very favorable results for catalyst recycling. ${ }^{5,6}$ Thus $\mathbf{1}$ has been heterogenized on polystyrenes, ${ }^{5 a-b}$ on dendritic supports, ${ }^{5-e}$ or on silicas. ${ }^{5 f, g}$ It has been modified by addition of sulfonate functions for biphasic catalysis, ${ }^{5 \mathrm{~h}, \mathrm{i}}$ immobilized in a polydimethoxysilane membrane, ${ }^{5 \mathrm{j}}$ or in room temperature ionic liquids (RTILs). ${ }^{6}$ The most promising result for high turn-over number (TON) has been obtained by immobilization on a PEG support, albeit with an ee lower than with the other methods. ${ }^{5 k, 1}$ 


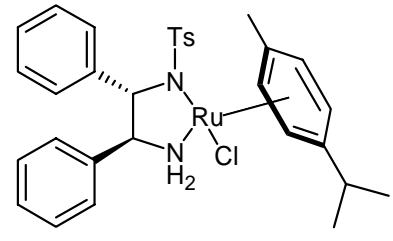

1

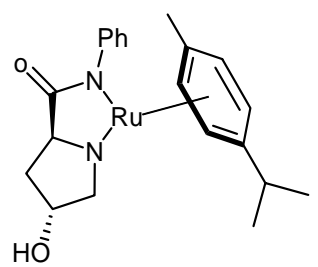

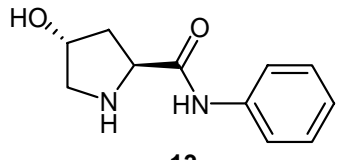

13

RTILs are interesting alternatives to conventional organic solvents as has been shown by numerous reports. ${ }^{7}$ We are interested in the use of RTILs as solvents in applications as various as electrosynthesis ${ }^{8 \mathrm{a}}$ enzymatic catalysis, ${ }^{8 \mathrm{~b}}$ metal oxide catalysis, ${ }^{8 \mathrm{c}}$ or organometallic catalysis. $^{8 \mathrm{~d}}$ When the right RTIL is chosen for a given reaction, not only it can lead to enhanced yields or reaction rates, but also improves the results of the work-up, from product separation to catalyst recycling. Herein we wish to report the immobilization of catalyst $\mathbf{2}$ and of the catalyst derived from precatalyst 1, in a variety of RTILs (Figure 1) for asymmetric transfer hydrogenation of acetophenone, and the successful recycling of these systems.
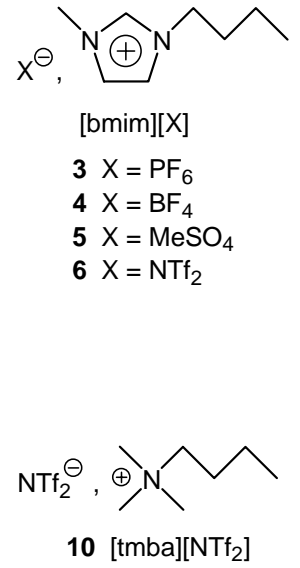

$5 \mathrm{X}=\mathrm{MeSO}_{4}$

$6 \mathrm{X}=\mathrm{NTf}_{2}$

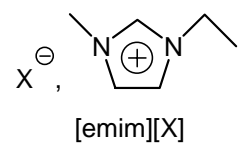

$7 \mathrm{X}=\mathrm{TfO}$ $8 \mathrm{X}=\mathrm{NTf}_{2}$

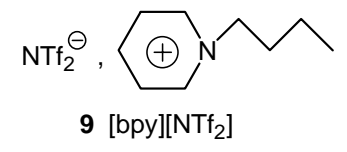

$9[\mathrm{bpy}]\left[\mathrm{NTf}_{2}\right]$

Figure 1. RTILs used in this study (bmim = 1-butyl-3-methylimidazolium, emim = 1-ethyl-3methylimidazolium, bpy $=\mathrm{N}$-butylpyridinium, tmba $=$ trimethylbutylammonium).${ }^{9-14}$

\section{Results and Discussion}

\section{Transfer hydrogenation with catalyst 2}

Use of 2 and related complexes for the asymmetric transfer hydrogenation of arylketones has been studied by Chung et al. ${ }^{15}$ We started from their experimental conditions, and substituted RTILs as solvent for dichloromethane (DCM) in the reduction of acetophenone (Scheme 1, condition A). ${ }^{16}$ Table 1 shows the results obtained for this reduction in DCM, [bmim][NTf $\left.{ }_{2}\right] \mathbf{6}$, [bpy] $\left[\mathrm{NTf}_{2}\right]$ 9, and [bmim] $\left[\mathrm{PF}_{6}\right] 3$ (entries 1-4). Use of [bmim] $\left.\mathrm{PF}_{6}\right]$ accelerates the conversion, in comparison to the use of $[\mathrm{bmim}]\left[\mathrm{NTf}_{2}\right]$ or to the standard reaction in DCM. Ee's are similar in the different solvents, except in $[\mathrm{bpy}]\left[\mathrm{NTf}_{2}\right]$, in which the addition is sluggish. The low vapor 
pressure of the RTILs allowed for the recycling of the catalytic system by bulb-to-bulb distillation of the 1-phenylethanol produced. The reactor can then be reloaded for another reaction. Table 1 shows the results obtained for five consecutive cycles in [bmim] $\left[\mathrm{PF}_{6}\right]$ (entries 4-8). Catalyst 2 retains a good activity and good ee's in this RTIL. After four recycles the observed ee has only diminished from 72 to $68 \%$, and its $\mathrm{TOF}_{1 / 2}{ }^{*}$ is still as high as 2.5 , which compares favorably to the $\mathrm{TOF}_{1 / 2}$ of 2.6 for the standard run in DCM (entry 1).

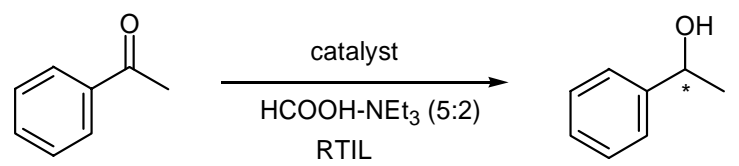

Scheme 1. Asymmetric transfer hydrogenation of acetophenone in RTILs with formic acid as the hydrogen donor. Conditions A (catalyst 2 generated in situ): $\left[\mathrm{Ru}\left(p \text {-cymene) } \mathrm{Cl}_{2}\right]_{2}\right.$ (0.04 eq), 13 (0.02 eq), RTIL (1L/eq), T=30 C. Conditions B: precatalyst 1 (0.005 eq), RTIL (0.75L/eq).

Table 1. Asymmetric transfer hydrogenation of acetophenone catalyzed by 2 (Scheme 1, conditions A)

\begin{tabular}{|c|c|c|c|c|c|c|}
\hline Entry & Solvent & Cycle $n^{\circ}$ & Time (h) & Conversion (\%) & $\mathrm{TOF}_{1 / 2}^{*}\left(\mathrm{~h}^{-1}\right)$ & $\mathrm{ee}^{\mathrm{a}}(\%)$ \\
\hline 1 & DCM & 1 & 23 & 99 & 2.6 & 71 \\
\hline 2 & {$[\mathrm{bmim}]\left[\mathrm{NTf}_{2}\right] \mathbf{6}$} & 1 & 23 & 98 & 2.7 & 71 \\
\hline 3 & {$[\mathrm{bpy}]\left[\mathrm{NTf}_{2}\right] \mathbf{9}$} & 1 & 22 & 50 & 1.1 & 65 \\
\hline 4 & {$[\mathrm{bmim}]\left[\mathrm{PF}_{6}\right] \mathbf{3}$} & 1 & 14 & 99 & 4.0 & 72 \\
\hline $5^{b}$ & {$[\mathrm{bmim}]\left[\mathrm{PF}_{6}\right] \mathbf{3}$} & 2 & 22 & 99 & 3.1 & 71 \\
\hline $6^{\mathrm{b}}$ & {$[\mathrm{bmim}]\left[\mathrm{PF}_{6}\right] \mathbf{3}$} & 3 & 22 & 99 & 3.0 & 71 \\
\hline $7^{\mathrm{b}}$ & {$[\mathrm{bmim}]\left[\mathrm{PF}_{6}\right] 3$} & 4 & 22 & 99 & 2.8 & 70 \\
\hline $8^{\mathrm{b}}$ & {$[\mathrm{bmim}]\left[\mathrm{PF}_{6}\right] 3$} & 5 & 22 & 99 & 2.5 & 68 \\
\hline
\end{tabular}

${ }^{\mathrm{a}} \mathrm{R}$ enantiomer.

${ }^{b}$ Recycling of the supported catalyst is performed by bulb-to-bulb distillation of the product.

\section{Transfer hydrogenation with precatalyst 1}

With this successful recycling of catalyst $\mathbf{2}$ in hand, we have proceeded with a detailed study of the recycling of $\mathbf{1}$ when immobilized in a variety of RTILs. We started from Noyori's original conditions, and added RTILs as solvent in the reduction of acetophenone (Scheme 1, conditions B). ${ }^{2 \mathrm{c}}$ Table 2 shows the results obtained for this reduction in a variety of RTILs. 
Table 2. Asymmetric transfer hydrogenation of acetophenone with precatalyst 1 (Scheme, conditions B)

\begin{tabular}{|c|c|c|c|c|c|c|c|}
\hline Entry & $\begin{array}{l}\text { Temp } \\
\left({ }^{\circ} \mathrm{C}\right)\end{array}$ & RTIL & Cycle $n^{\circ}$ & $\begin{array}{l}\text { Time } \\
\text { (h) }\end{array}$ & $\begin{array}{c}\text { Conversion } \\
(\%)\end{array}$ & $\begin{array}{c}\mathrm{TOF}_{1 / 2}{ }^{*} \\
\left(\mathrm{~h}^{-1}\right)\end{array}$ & $\mathrm{ee}^{\mathrm{a}}(\%)$ \\
\hline 1 & 30 & No RTIL added & 1 & 23 & 99 & 22.2 & 97 \\
\hline 2 & 30 & {$[\mathrm{bmim}]\left[\mathrm{PF}_{6}\right] \mathbf{3}$} & 1 & 31 & 97 & 11.6 & 96 \\
\hline $3^{\mathrm{b}}$ & 30 & {$[\mathrm{bmim}]\left[\mathrm{PF}_{6}\right] 3$} & 2 & 50 & 92 & 5.4 & 95 \\
\hline $4^{\mathrm{b}}$ & 30 & {$[\mathrm{bmim}]\left[\mathrm{PF}_{6}\right] 3$} & 3 & 95 & 46 & / & 89 \\
\hline 5 & 30 & {$[\mathrm{bmim}]\left[\mathrm{MeSO}_{4}\right] \mathbf{5}$} & 1 & 48 & 19 & l & 85 \\
\hline 6 & 30 & {$[\mathrm{bmim}]\left[\mathrm{NTf}_{2}\right] \mathbf{6}$} & 1 & 27 & 98 & 14.9 & 96 \\
\hline $7^{\mathrm{b}}$ & 30 & {$[\mathrm{bmim}]\left[\mathrm{NTf}_{2}\right] \mathbf{6}$} & 2 & 21 & 58 & 5.5 & 96 \\
\hline 8 & 30 & {$[\mathrm{emim}]\left[\mathrm{NTf}_{2}\right] \mathbf{8}$} & 1 & 48 & 91 & 5.0 & 95 \\
\hline 9 & 30 & {$[\mathrm{tmba}]\left[\mathrm{NTf}_{2}\right] \mathbf{1 0}$} & 1 & 26 & 98 & 15.6 & 97 \\
\hline $10^{\mathrm{b}}$ & 30 & {$[\mathrm{tmba}]\left[\mathrm{NTf}_{2}\right] \mathbf{1 0}$} & 2 & 41 & 99 & 7.9 & 97 \\
\hline $11^{\mathrm{b}}$ & 30 & {$[\mathrm{tmba}]\left[\mathrm{NTf}_{2}\right] \mathbf{1 0}$} & 3 & 94 & 99 & 4.9 & 97 \\
\hline $12^{\mathrm{b}}$ & 30 & {$[\mathrm{tmba}]\left[\mathrm{NTf}_{2}\right] \mathbf{1 0}$} & 4 & 50 & 56 & 2.3 & 96 \\
\hline 13 & 40 & No RTIL added & 1 & 8 & 99 & 35.7 & 97 \\
\hline 14 & 40 & {$[\mathrm{tmba}]\left[\mathrm{NTf}_{2}\right] \mathbf{1 0}$} & 1 & 9 & 99 & 33.3 & 97 \\
\hline $15^{\mathrm{b}}$ & 40 & {$[\mathrm{tmba}]\left[\mathrm{NTf}_{2}\right] \mathbf{1 0}$} & 2 & 27 & 98 & 13.5 & 97 \\
\hline $16^{\mathrm{b}}$ & 40 & {$[\mathrm{tmba}]\left[\mathrm{NTf}_{2}\right] \mathbf{1 0}$} & 3 & 48 & 83 & 5.2 & 97 \\
\hline 17 & 40 & {$\left[\mathrm{MeBu}_{3} \mathrm{P}\right]\left[\mathrm{NTf}_{2}\right] \mathbf{1 1}$} & 1 & 11 & 99 & 30.3 & 97 \\
\hline $18^{\mathrm{b}}$ & 40 & {$\left[\mathrm{MeBu}_{3} \mathrm{P}\right]\left[\mathrm{NTf}_{2}\right] \mathbf{1 1}$} & 2 & 21 & 97 & 22.7 & 95 \\
\hline $19^{\mathrm{b}}$ & 40 & {$\left[\mathrm{MeBu}_{3} \mathrm{P}\right]\left[\mathrm{NTf}_{2}\right] \mathbf{1 1}$} & 3 & 70 & 94 & 5.4 & 91 \\
\hline 20 & 40 & $\begin{array}{c}{\left[\mathrm{C}_{14} \mathrm{Hex}_{3} \mathrm{P}\right]\left[\mathrm{NTf}_{2}\right]} \\
\mathbf{1 2}\end{array}$ & 1 & 20 & 97 & 20 & 97 \\
\hline $21^{\mathrm{b}}$ & 40 & $\begin{array}{c}{\left[\mathrm{C}_{14} \mathrm{Hex}_{3} \mathrm{P}\right]\left[\mathrm{NTf}_{2}\right]} \\
\mathbf{1 2}\end{array}$ & 2 & 24 & 64 & 5.7 & 95 \\
\hline 22 & 50 & {$[\mathrm{bmim}]\left[\mathrm{BF}_{4}\right] 4$} & 1 & 40 & $<1$ & I & I \\
\hline 23 & 60 & [emim][TfO] 7 & 1 & 24 & 0 & I & I \\
\hline 24 & 40 & {$[\mathrm{tmba}]\left[\mathrm{NTf}_{2}\right] \mathbf{1 0}$} & 1 & 9 & 99 & 33.3 & 97 \\
\hline $25^{\mathrm{c}, \mathrm{d}}$ & 40 & {$[\mathrm{tmba}]\left[\mathrm{NTf}_{2}\right] \mathbf{1 0}$} & 2 & 24 & 97 & 17.9 & 97 \\
\hline $26^{\mathrm{c}, \mathrm{e}}$ & 40 & {$[\mathrm{tmba}]\left[\mathrm{NTf}_{2}\right] \mathbf{1 0}$} & 3 & 30 & 82 & 7.1 & 96 \\
\hline
\end{tabular}

${ }^{\mathrm{a}} \mathrm{S}$ enantiomer.

${ }^{b}$ Recycling of the supported catalyst is performed by bulb-to-bulb distillation of the product.

${ }^{\mathrm{c}}$ Recycling of the supported catalyst is performed by liquid/liquid extraction of the product.

${ }^{\mathrm{d}}$ Ruthenium leached during the extractions: $1.5 \%$.

${ }^{\mathrm{e}}$ Ruthenium leached during the extractions: $1.3 \%$.

Contrary to catalyst 2, use of RTILs as solvents with $\mathbf{1}$ does not accelerate the transfer hydrogenation. In fact, the catalyst is strongly inhibited by the hydrophilic RTILs [bmim] $\left[\mathrm{BF}_{4}\right]$ 4, [bmim] $\left[\mathrm{MeSO}_{4}\right] 5$ and [emim][TfO] 7 (compare entries 1, 5, 22, 23). Hydrophobic ionic 
liquids with $\mathrm{PF}_{6}$ or $\mathrm{NTf}_{2}$ counter-anions slow down the reaction (compare entries 1, 2, 6, 7, 9, or entries 13, 14, 17, 20), but good ee's are obtained. For the RTILs giving the best results ([bmim] $\left[\mathrm{PF}_{6}\right],[\mathrm{bmim}]\left[\mathrm{NTf}_{2}\right],[\mathrm{tmba}]\left[\mathrm{NTf}_{2}\right] \mathbf{1 0},\left[\mathrm{MeBu}_{3} \mathrm{P}\right]\left[\mathrm{NTf}_{2}\right] \mathbf{1 1},\left[\mathrm{C}_{14} \mathrm{Hex}_{3} \mathrm{P}\right]\left[\mathrm{NTf}_{2}\right]$ 12), the catalytic systems have been reused after bulb-to-bulb distillation of the 1-phenylethanol as described previously. Good ee's were maintained over consecutive recycles in those RTILs (Table 2, entries 2-4, 6-7, 9-12, 14-16, 17-19, 20-21). In the RTIL [tmba][NTf 2 in particular, the catalytic system can be recycled three times and gives a total TON higher than 700, with an ee higher than 96\% for the last run (entries 9-12).

Instead of bulb-to-bulb distillation of the 1-phenylethanol produced, the catalytic system can also be recycled after liquid/liquid extraction. We have chosen [tmba][NTf 2 as immobilization solvent, on account of the preceding results obtained with this RTIL. Volatile organic solvents immiscible with $[\mathrm{tmba}]\left[\mathrm{NTf}_{2}\right]$ are few; we have retained three (the partition coefficients of 1-phenylethanol between these solvents and [tmba] $\left.\mathrm{NTf}_{2}\right]$ are given in

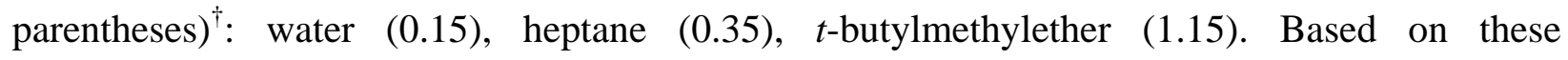
coefficients $t$-butylmethylether has been chosen for the extractions. The results (Table 2, entries 24-26) show a deactivation of the catalyst which parallels the deactivation observed with recycling by bulb-to-bulb distillation (Table 2, entries 14-16), but once again the ee is well preserved after the recycles. The low leaching of ruthenium during the extractions prompted us not to graft the catalyst on an ionic support. This grafting has been achieved by others but did not lead to a clear improvement. ${ }^{6}$

However it would be interesting if one could immobilize an analogue of triethylamine, because large quantities of triethylamine are generally used in transfer hydrogenations when formic acid is the hydrogen donor, and they are lost during the recycling. For a catalysis taking place in [tmba][NTf 2 ], 14 and $\mathbf{1 5}$ seem to be promising candidates. The calculated pKa of these bases (respectiveley 10.5 and 10.6, at zero ionic strength) are similar to that of triethylamine (10.6). ${ }^{17}$ Accordingly, triethylamine has been substituted by bases 14 and $\mathbf{1 5}$ for transfer hydrogenation of acetophenone, but neither of them allowed the catalysis to occur. 14 and 15 may lack basicity in the very ionic reaction medium. Studies employing 14 as a base in the Heck coupling did however demonstrate a similar reactivity as triethylamine. ${ }^{18}$

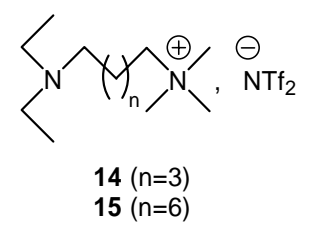




\section{Conclusions}

Catalyst 2, employed in the asymmetric transfer hydrogenation of acetophenone, brings about accelerated catalysis when it is immobilized in $[\mathrm{bmim}]\left[\mathrm{PF}_{6}\right]$. In addition it has been reused four times with preservation of enantiomeric excess, and only a moderate decrease of activity.

Catalyst 1 also allows efficient recycling when immobilized in certain RTILs. Thus we have shown that its immobilization in [tmba] $\left[\mathrm{NTf}_{2}\right]$ allows three recycles and the reduction of acetophenone with a total TON higher than 700 and an ee of $96 \%$ in the last cycle. In comparison to catalyst $\mathbf{1}$ supported on insoluble polymers, in dendritic structures, or with sulfonate functional groups, $\mathbf{1}$ immobilized in [tmba] $\left[\mathrm{NTf}_{2}\right]$ gives faster rates, a higher total TON and better ee's. ${ }^{5 a-e, h, i}$ The TON for immobilization in RTILs is slightly lower than with zeolite immobilization, ${ }^{5 f, g}$ and really lower than with PEG immobilization, ${ }^{5 k, l}$ but immobilization in RTILs allows the best enantioselectivity.

\section{Experimental Section}

General Procedures. All glassware was oven dried prior to use. Acetophenone was distilled and stored under an argon atmosphere and protected from light. Preparation of ionic liquids [bmim] [PF6 $],{ }^{9}$ [emim][TfO $],{ }^{10}$ [bmim] $[\mathrm{BF} 4],{ }^{11}$ [bmim] $[\mathrm{NTf} 2],{ }^{10}$ [emim][Br] ${ }^{10}$ [emim][NTf2],10

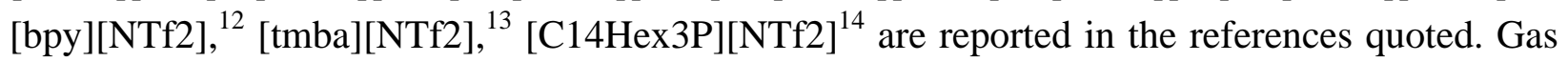
liquid chromatography (GLC) was carried out on a Fisons 8130 gas chromatograph using N2 as carrier gas and a Chrompack CP-Chiralsil-Dex CB column (R enantiomer of 1-phenylethanol elutes first). Ruthenium leaching was measured by ICP.

Typical procedure for the asymmetric transfer hydrogenation of acetophenone with catalyst 2 in a formic acid - triethylamine - RTIL mixture, and recycling of the catalytic system. $18.4 \mathrm{mg}(0.03 \mathrm{mmol})$ of $\left[\mathrm{Ru}(p \text {-cymene }) \mathrm{Cl}_{2}\right]_{2}$ and $12.4 \mathrm{mg}(0.06 \mathrm{mmol})$ of $(2 S, 4 R)-4-$ hydroxyprolinanilide ligand $\mathbf{1 3}$ are dissolved in $3 \mathrm{~mL}$ DCM, then transferred in a Schlenk tube containing $3 \mathrm{~mL}$ of a RTIL which has previously been dried under reduced pressure $\left(10^{-2} \mathrm{~mm}\right.$ $\mathrm{Hg})$ at $100^{\circ} \mathrm{C}$ for 2 hours. After the DCM has been eliminated $\left(10^{-2} \mathrm{~mm} \mathrm{Hg}\right.$ at $50^{\circ} \mathrm{C}$ for $\left.30 \mathrm{~min}\right)$, the Schlenk tube is stirred at the temperature chosen for the reaction, and $1.56 \mathrm{~g}$ of a 5:2 mixture of formic acid and triethylamine (18 mmol of formic acid) is introduced. After 30 min (time necessary for the in situ formation of the catalyst), $350 \mu \mathrm{L}$ (3 mmol) of acetophenone are added (initial moment for reaction monitoring). The reaction monitoring is carried out by filtration of an aliquot of the reaction medium on silica, and its analysis by GLC. Recycling of the catalytic system is done by bulb-to-bulb distillation of the product $\left(10^{-2} \mathrm{~mm} \mathrm{Hg}\right.$ at $60-70^{\circ} \mathrm{C}$ for 1 hour $)$. The reactor is then reloaded with a 5:2 mixture of formic acid and triethylamine (1.56 g), and with acetophenone $(350 \mu \mathrm{L})$. 
Typical procedure for asymmetric transfer hydrogenation of acetophenone with precatalyst 1 in a formic acid - triethylamine - RTIL mixture, and recycling of the catalytic system. $12.7 \mathrm{mg}(0.02 \mathrm{mmol})$ of precatalyst 1 are dissolved in $2.10 \mathrm{~g}$ of a 5:2 mixture of formic acid and triethylamine (24 mmol of formic acid), then transfered in a Schlenk tube containing $3 \mathrm{~mL}$ of RTIL which has previously been dried $\left(10^{-2} \mathrm{~mm} \mathrm{Hg}\right.$ at $100^{\circ} \mathrm{C}$ for 2 hours). The Schlenk tube is stirred at the chosen temperature and $470 \mu \mathrm{L}(4 \mathrm{mmol})$ acetophenone are added (initial moment for the reaction monitoring). The reaction monitoring is done as mentioned above. The recycling of the catalytic system can be done by bulb-to-bulb distillation (as mentioned above). Alternatively it can be done by extraction of the product with ten times 3 $\mathrm{mL} t$-butylmethylether, followed by drying of the RTIL under reduced pressure for 2 hours. The reactor is then reloaded with a mixture of formic acid and triethylamine (2.10 g) and with acetophenone $(470 \mu \mathrm{L})$.

\section{Acknowledgements}

We thank P. Guénot and CRMPO (University of Rennes) for HRMS analysis, and O. Guillou (INSA Rennes) for ICP experiments. J.M.J. thanks the CNRS and Rhodia for a Ph.D. grant.

\section{References and Notes}

* $\mathrm{TOF}_{1 / 2}$ is the average turn-over frequency at $50 \%$ conversion. It is calculated from the reaction time corresponding to $50 \%$ conversion.

$\dagger \mathrm{K}=$ (\%w of 1-phenylethanol in the volatile solvent) / (\%w of 1-phenylethanol in the RTIL). Measured by GC with an external standard.

1. For reviews on asymmetric transfer hydrogenation, see: (a) Ohkuma, T.; Noyori, R. In Hydrogenation of Carbonyl Groups; Jacobsen, E. N.; Pfaltz, A.; Yamamoto, H., Eds. Comprehensive Asymmetric Catalysis. Springer-Verlag: Berlin, 1999; p 199. (b) Ohkuma, T.; Noyori, R. In Hydrogenation of Carbonyl Groups; Jacobsen, E. N.; Pfaltz, A.; Yamamoto, H., Eds. Comprehensive Asymmetric Catalysis: Supplement 1. Springer-Verlag: Berlin, 2004; pp 1. (c) Palmer, M. J.; Wills M. Tetrahedron: Asymmetry 1999, 10, 2045. (d) Everaere, K.; Mortreux, A.; Carpentier, J.-F. Adv. Synth. Catal. 2003, 345, 67. (e) Gladiali S.; Alberico, E. Chem. Soc. Rev. 2006, 35, 226.

2. For examples of transfer hydrogenations catalyzed by $\mathbf{1}$ or related complexes, see (a) Hashiguchi, S.; Fujii, A.; Takehara, J.; Ikariya, T.; Noyori, R. J. Am. Chem. Soc. 1995, 117, 7562. (b) Takehara, J.; Hashiguchi, S.; Fujii, A.; Inoue, S.; Ikariya, T.; Noyori, R. Chem. Commun. 1996, 233. (c) Fujii, A.; Hashiguchi, S.; Uematsu, N.; Ikariya, T.; Noyori, R. J. Am. Chem. Soc. 1996, 118, 2521. (d) Hashiguchi, S.; Noyori, R. Acc. Chem. Res. 1997, 30, 
97. (e) Matsumura, K.; Hashiguchi, S.; Uematsu, N.; Ikariya, T.; Noyori, R. J. Am. Chem. Soc. 1997, 119, 8738. (f) Haack, K. J.; Hashiguchi, S.; Fujii, A.; Ikariya, T.; Noyori, R. Angew. Chem. Int. Ed. 1997, 36, 285. (g) Hashiguchi, S.; Fujii, A.; Haack, K. J.; Matsumura, K.; Ikariya, T.; Noyori, R. Angew. Chem. Int. Ed. 1997, 36, 288. (h) Murata, K.; Okano, K.; Miyagi, M.; Iwane, H.; Noyori, R.; Ikariya, T. Org. Lett. 1999, 1, 1119.

3. For examples of transfer hydrogenations catalyzed by other [Ru(arene)(diamine)] complexes, see (a) Püntener, K.; Schwink, L.; Knochel, P. Tetrahedron Lett. 1996, 37, 8165. (b) Rhyoo, H. Y.; Yoon Y.-A.; Park, H.-J.; Chung, Y. K. Tetrahedron Lett. 2001, 42, 5045. (c) Rhyoo, H. Y.; Park, H.-J.; Chung Y. K. Chem. Commun. 2001, 2064. (d) Mohar, B.; Valleix, A.; Desmurs, J.-R.; Felemez, R.; Wagner, A.; Mioskowski, C. Chem. Commun. 2001, 2572. (e) Cossy, J.; Eustache, F.; Dalko, P. I. Tetrahedron Lett. 2001, 42, 5005. (f) Faller, J. W.; Lavoie, A. R. Organometallics 2001, 20, 5245. (g) Taran, F.; Gauchet, C.; Mohar, B.; Meunier, S.; Valleix, A.; Renard, P. Y.; Créminon, C.; Grassi, J.; Wagner, A.; Mioskowski, C. Angew. Chem. Int. Ed. 2002, 41, 124. (h) Šterk, D.; Stephan, M. S.; Mohar, B. Tetrahedron: Asymmetry 2002, 13, 2605. (i) Hannedouche, J.; Clarkson, G. J.; Wills, M. J. Am. Chem. Soc. 2004, 126, 986. (j) Hayes, A.; Clarkson, G.; Wills M. Tetrahedron: Asymmetry 2004, 15, 2079.

4. For reviews on chiral catalyst immobilization, see (a) De Vos, D. E.; Vankelecom, I. F. J.; Jacobs P. A., Eds. Chiral Catalyst Immobilization and Recycling. Wiley-VCH: Weinheim, 2000. (b) Fan, Q.-H.; Li Y.-M.; Chan, A. S. C. Chem. Rev. 2002, 102, 3385. (c) Song, C. E.; Lee, S.-G. Chem. Rev. 2002, 102, 3495.

5. For examples of complex $\mathbf{1}$ immobilization and its use in transfer hydrogenation, see (a) ter Halle, R.; Schultz, E.; Lemaire, M. Synlett 1997, 1257. (c) Bayston, D. J.; Travers, C. B.; Polywka, M. E. C. Tetrahedron: Asymmetry 1998, 9, 2015. (c) Chen, Y.-C.; Wu, T.-F.; Deng, J.-G.; Liu, H.; Jiang, Y.-Z.; Choi, M. C. K.; Chan, A. S. C. Chem. Commun. 2001, 1488. (d) Chen, Y.-C.; Wu, T.-F.; Deng, J.-G.; Liu, H.; Cui, X.; Zhu, J.; Jiang, Y.-Z.; Choi, M. C. K.; Chan, A. S. C. J. Org. Chem. 2002, 67, 5301. (e) Chen, Y.-C.; Wu, T.-F.; Jiang, L.; Deng, J.-G.; Liu, H.; Zhu, J.; Jiang Y.-Z. J. Org. Chem. 2005, 70, 1006. (f) Liu, P. N.; Gu, P. M.; Wang, F.; Tu, Y. Q. Org. Lett. 2004, 6, 169. (g) Liu, P. N.; Deng, J. G.; Tu, Y. Q.; Wang, S. H. Chem. Commun. 2004, 2070. (h) Bubert, C.; Blacker, J.; Brown, S. M.; Crosby, J.; Fitzjohn, S.; Muxworthy, J. P.; Thorpe, T.; Williams, J. M. J. Tetrahedron Lett. 2001, 42, 4037. (i) Ma, Y.; Liu, H.; Chen, L.; Cui, X.; Zhu, J.; Deng, J. Org. Lett. 2003, 5, 2103. (j) De Smet, K.; Pleysier, A.; Vankelecom, I. F. J.; Jacobs, P. A. Chem. Eur. J. 2003, 9, 334. (k) Li, X.; Chen, W.; Hems, W.; King, F.; Xiao, J. Tetrahedron Lett. 2004, 45, 951. (l) Li, X.; Wu, X.; Chen, W.; Hancock, F. E.; King, F.; Xiao, J. Org. Lett. 2004, 6, 3321.

6. After our work was finished, which was first communicated at the JCO (Palaiseau, France) in September 2004, two publications appeared where 1 was immobilized in 1-butyl-2,3dimethylimidazolium ionic liquids for transfer hydrogenation of acetophenone: (a) Geldbach, T. J.; Dyson, P. J. J. Am. Chem. Soc. 2004, 126, 8114. (b) Kawasaki I.; Tsunoda 
K.; Tsuji, T.; Yamaguchi T.; Shibuta H.; Uchida N.; Yamashita M.; Ohta S. Chem. Commun. 2005, 2134.

7. For reviews on RTILs and their use in synthesis, see (a) Jain, N.; Kumar, A.; Chauhan, S.; Chauhan, S. M. S. Tetrahedron 2005, 61, 1015. (b) Song C. E. Chem. Commun. 2004, 1033. (c) Wasserscheid, P.; Welton, T., Eds. Ionic Liquids in Synthesis. Wiley-VCH: Weinheim, 2003. (d) Baudequin, C.; Baudoux, J.; Levillain, J.; Cahard, D.; Gaumont, A.-C.; Plaquevent, J.-C. Tetrahedron: Asymmetry 2003, 14, 3081. (e) Dupont, J.; de Souza, R. F.; Suarez P. A. Z. Chem. Rev. 2002, 102, 3667.

8. (a) Lagrost, C.; Carrie, D.; Vaultier, M.; Hapiot, P. J. Phys. Chem. A 2003, 107, 745. (b) Lozano, P.; De Diego, T.; Carrie, D.; Vaultier, M.; Iborra, J. L. Biotechnol. Prog. 2003, 19, 380. (c) Gmouh, S.; Yang, H.; Vaultier, M. Org. Lett. 2003, 5, 2219. (d) Berthod, M.; Joerger, J.-M.; Mignani, G.; Vaultier, M.; Lemaire, M. Tetrahedron: Asymmetry 2004, 15, 2219.

9. Fuller, J.; Breda, A. C.; Carlin, R. T. J. Electroanal. Chem. 1998, 459, 29.

10. Bonhôte, P.; Dias, A.-P.; Papageorgiou, N.; Kalyanasundaram, K.; Grätzel, M. Inorg. Chem. 1996, 35, 1168.

11. Huddleston, J. G.; Visser, A. E.; Reichert, W. M.; Willauer, H. D.; Broker, G. A.; Rogers, R. D. Green Chem. 2001, 3, 156.

12. Noda, A.; Hayamizu, K.; Watanabe, M. J. Phys. Chem. B. 2001, 105, 4603.

13. Tiyapiboonchaiya, C.; Mac Farlane, D. R.; Sun, D. R.; Forsyth, M. Macromolecular Chemistry and Physics 2002, 203, 1906.

14. Hardacre, C.; Holbrey, J. D.; Katdare, S. P.; Seddon, K. R. Green Chem. 2002, 4, 143.

15. Rhyoo, H. Y.; Park, H.-J.; Chung, Y. K. Chem. Commun. 2001, 2064.

16. Rhyoo, H. Y.; Yoon, Y.-A; Park, H.-J.; Chung, Y. K. Tetrahedron Lett. 2001, 42, 5045.

17. ACD/pKa, version 8.02, Advanced Chemistry Development, Inc., Toronto ON, Canada.

18. Vaultier,M.; Gmouh,S., WO2004029004. Vaultier, M. ; Gmouh, S. ; Hassine, F., WO 2005005345. 